ECCOMAS

\section{Proceedia}

COMPDYN 2021

$8^{\text {th }}$ ECCOMAS Thematic Conference on Computational Methods in Structural Dynamics and Earthquake Engineering

M. Papadrakakis, M. Fragiadakis (eds.) Streamed from Athens, Greece, 28 - 30 June 2021

\title{
NUMERICAL MODELING OF A ROCKING AND SLIDING CYLINDRICAL COLUMN UNDER SEISMIC EXCITATION
}

\author{
Antonios A. Katsamakas ${ }^{1}$ and Michalis F. Vassiliou ${ }^{2}$ \\ ${ }^{1}$ Ph.D. Candidate, Chair of Seismic Design and Analysis, IBK, ETH Zurich \\ Stefano-Franscini-Platz 5 \\ 8093 Zürich \\ Switzerland \\ e-mail: katsamakas@ibk.baug.ethz.ch \\ ${ }^{2}$ Assistant Professor, Chair of Seismic Design and Analysis, IBK, ETH Zurich \\ Stefano-Franscini-Platz 5 \\ 8093 Zürich \\ Switzerland \\ e-mail: vassiliou@ibk.baug.ethz.ch
}

\begin{abstract}
This paper presents a finite element (FE) modeling approach for simulating the $3 D$ response of a free-standing cylindrical column. The model is validated against experimental results, which involved testing of the cylindrical steel column under a set of 100 bidirectional ground motions. The specimen was free-standing and allowed to slide and rock in all directions. Both the tested specimen and the shake table platen were stiff enough to be modeled as rigid. The contact surface was modeled using Coulomb friction for the tangential behavior and stiff contact for the normal direction. Two energy dissipation mechanisms were modelled; friction and radiation damping. Since Rayleigh damping is not directly linked to the physical problem, it was set equal to zero.

It has been proven that the response of a single column to an individual ground motion is a chaotic and unpredictable problem. Therefore, a statistical approach was utilized to compare the numerical to the experimental results, using the cumulative distribution function (CDF) for the main response quantities (i.e., maximum displacement at the top of the column and residual displacement), demonstrating satisfying agreement.

The influence of the friction coefficient was assessed through an extensive sensitivity analysis using non-linear time-history analyses. Results proved that the statistics of the response only smoothly depend on the exact value of the friction coefficient even though the response to an individual ground motion seems chaotic.
\end{abstract}

Keywords: Rocking Columns, Finite Elements, Statistical Validation, Sensitivity Analysis, Free-Standing Equipment 


\section{INTRODUCTION}

Rocking structures are the ones that are allowed to uplift. Under ground motion, uplifting occurs when:

$$
\ddot{u}_{g}>g \tan \alpha
$$

where $\ddot{u}_{g}$ is the ground acceleration, $g$ is the gravity acceleration, and $\alpha$ is the slenderness of the block (Figure 1). It is assumed that the sliding surface is sufficiently rough to prevent sliding. This uplifting effect acts as a fuse, limiting the inertial forces transmitted to the superstructure. After uplift, a rocking oscillator demonstrates negative stiffness, making the description of such systems significantly different to the conventional ones.

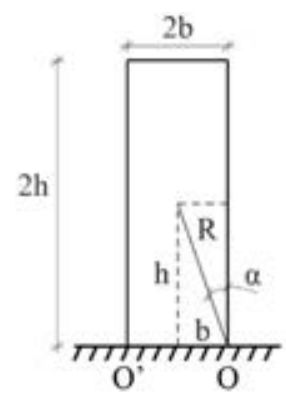

Figure 1. Geometric properties of a rocking block.

The first analytical study of this phenomenon is dated back to 1885 [1,2]. However, rocking structures have been systematically studied after 1963, when Housner published his seminal paper [3] where two main properties of the rocking structures were elucidated: i) out of two geometrically similar rocking blocks (same $\alpha$ ) the larger one (larger $R$ ) can survive an excitation which will topple the smaller one ii) longer period ground motions have a higher overturning potential [3].

The rocking oscillator has been used to describe the dynamic behavior of free-standing equipment [4-16], masonry structures [17-26] and ancient temples [27-34]. Rocking is also a promising seismic response modification technique, both for bridges and buildings, with practical applications in the former USSR and New Zealand. Applications in buildings may comprise a soft-rocking-story mechanism [35-37], or a rocking wall [38, 39], whereas in bridges, rocking piers [40-56]. Several analytical studies investigated the response of rocking structures combined with external dampers or restraining tendons [57-60]. The influence of the flexibility of the rocking body was also studied, both analytically and experimentally [61-65].

The analytical model proposed by Housner describes the planar response of a rigid rocking body when subjected to one-directional excitation. However, under seismic excitation, rocking structures are subjected to bidirectional (or three-directional when the vertical acceleration is considered) excitation [66-69]. Under these conditions, an unanchored body may rock in $3 \mathrm{D}$ dimensions (wobble). When it is not restrained, it may also slide out of its initial position or completely detach from the support.

This study aims at developing a practical three-dimensional finite element model to predict the response of free-standing cylindrical rocking columns. The validity of the proposed model is assessed by statistically comparing numerical and experimental results. The experimental results comprise 100 shake table tests, using a cylindrical steel column with a slenderness $(\alpha)$ of 0.2. The number of tests performed is large enough to create an experimental benchmark 
dataset, which could be used for a statistical comparison. The specimen was subjected to twodimensional excitation, and it was free to slide, rock and wobble in all directions. As the column is free to slide and wobble out of its original position, it serves for validation of numerical models used for the description of the seismic behavior of unanchored equipment, rather than of structures that use rocking as a seismic isolation strategy, where the rocking members would not be allowed to slide.

\section{STATISTICAL VALIDATION}

Rocking is often characterized as "chaotic", in the sense that the response of rocking objects is sensitive to the initial conditions [70], often making tests non-repeatable. Therefore, validating numerical models in a deterministic way does not even make sense.

Bachmann et al. [71] and Del Guidice et al. [72,73] claimed that validating a numerical model using a single ground motion is a sufficient but not necessary validation procedure. The seismic response is inherently stochastic since the excitation is stochastic. Therefore, a statistical (and not a deterministic) validation of the numerical model is proposed. During this statistical validation, the statistical distributions of the main response quantities of the model and the experiments are compared. This procedure requires an experimental benchmark dataset, where the same (or identical specimens) are excited by an ensemble of ground motions. Afterwards, a numerical model is used to create another dataset, using the same ensemble of excitations. The validity of the numerical model is assessed by comparing the Cumulative Distribution Function (CDF) of these two datasets for the same response quantities (i.e., maximum displacement at the top and residual displacement). This validation test is weaker (and easier to pass), yet sufficient for earthquake engineering applications.

\section{NUMERICAL STUDIES OF ROCKING STRUCTURES: RESULTS OF A BLIND PREDICTION CONTEST}

During the last decade, both FEM and DEM numerical models were developed to predict the rocking problem [74-79]. A recent blind prediction contest organized by ETH Zurich, the University of Bristol and the Pacific Earthquake Engineering Research (PEER) Center, shed light on the efficiency of numerical models used to describe the statistical response of a rocking podium structure $[80,81]$. Unlike the tests discussed in this paper, the tests of $[80,81]$ concerned a rocking podium structure that was restrained not to slide or wobble out of its original position. Thirteen contestants participated, using FEM, DEM, and analytical rigid-body models $[80,82-83]$. One of the important outcomes of this contest is that there is no basis for recommending FEM or DEM to model the response of wobbling structures; the accuracy of these models depends on the modeling assumptions. Moreover, it was proven that even though the winning models precisely captured the Cumulative Distribution Function of the maxima of the responses to each set of excitations, they were unable to accurately predict the response to each individual ground motion.

\section{EXPERIMENTAL PROCEDURE}

This section briefly presents an experimental investigation designed at ETH Zurich and carried out at EQUALS Lab, University of Bristol [84]. This investigation includes 115 shake table tests of cylindrical free-standing rocking bodies, which were free to slide and rock in all directions. More details about the tests can be found in [84]. From the various free-standing columns which were experimentally tested (Figure 2), this paper utilizes the results of one cylindrical column to assess the efficiency of the proposed FE model (Figure 3, right). The ex- 
perimental results from [84] served as an experimental (benchmark) dataset, to assess the proposed FE model.

The experimental results of [84] serve for model validation and were not chosen to represent specific free-standing rocking equipment. The specimens were designed to remain elastic after each test, so the same specimen could be excited with a large number of earthquake excitations to create a database suitable for a statistical validation. The specimens were made of round steel pipes, with different dimensions and slenderness.

The rocking response was induced by a di-directional dynamic excitation using a shake table. The applied ground motions were synthesized using a spectral version of the Rezaeian and Der Kiureghian stochastic ground motion model [85-86]. The 1989 Loma Prieta UCSC Lick Observatory ground motion record was used as a seed ground motion to generate an ensemble of 100 ground motions. The ground motions were scaled, with the frequency of ground motions increased by 2 without changing the amplitude. Therefore, in the prototype scale, the columns are 4 times larger.

\section{NUMERICAL MODEL}

The finite element software ABAQUS [87] was utilized to perform the analysis. The model comprised the cylindrical rocking body and a moving flat base-slab. The moving flat base emulates the top surface of the shake table. Both the rocking column and the flat base were modeled as rigid, since they were stiff enough and demonstrated no damage after testing. The flat base-slab was vertically supported by a spring-dashpot system to simulate the vertical stiffness of the shake-table platform and the radiation/impact damping mechanism (Figure 3, Left). Its rotation was constrained and set equal to zero. This approach was previously used in [88] in an effort to model radiation/impact damping, and it was shown that that in the planar case it leads to Housner's solution, as long as the stiffness of the spring is relatively high. Therefore, the spring constant was set to $10^{9} \mathrm{~N} / \mathrm{m}$ so that the pre-uplift vertical eigenperiod of the system is $0.001 \mathrm{sec}$. All rotations of the base were fixed. To apply the ground motion, the base moved parallel to $\mathrm{x}$ and $\mathrm{y}$ axis.

A uniform mesh with a size of $5 \mathrm{~mm}$ was utilized in all analyses. A 4-node 3D rigid quadrilateral finite element was used both for the rocking column and the flat base. The motion of the specimen was monitored with a reference point at the top of the column. The contact surface was simulated using Coulomb friction for the tangential behavior and ABAQUS stiff contact [87] for the normal direction. An explicit scheme with a fixed time increment of $10^{-6}$ sec was used in all cases.

The developed numerical model considers two main damping mechanisms; friction and radiation/impact damping. Inherent Rayleigh damping is set to zero since this energy dissipation mechanism is inconsistent with the physical problem. Energy dissipation through friction is considered through the friction coefficient, whereas radiation damping through the utilized dashpot. Neither the friction $(\mu)$ nor the dashpot $(\zeta)$ coefficient was known a priori; the influence of the friction coefficient was assessed through an extensive parametric analysis employing non-linear time history analysis. 


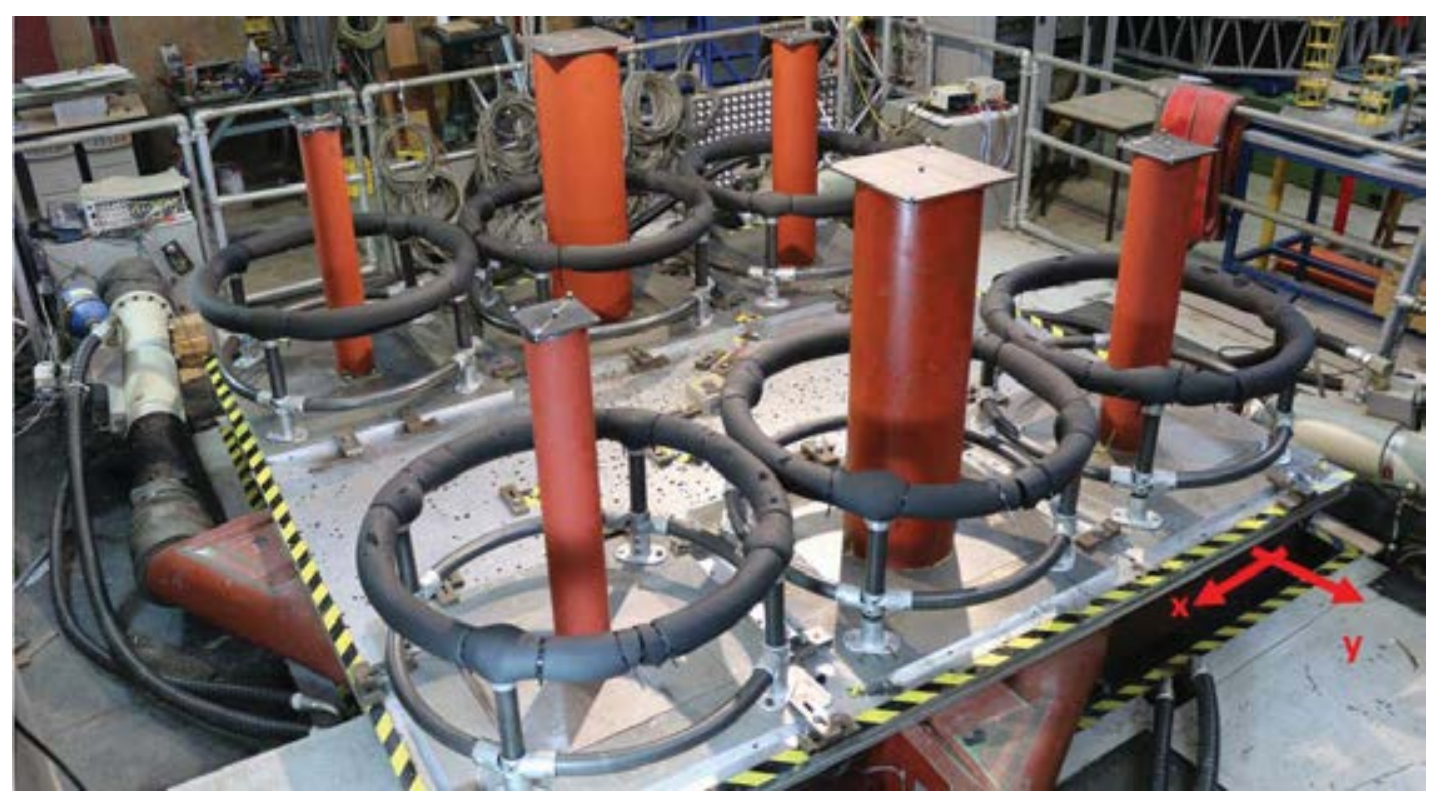

Figure. 2. Free-standing rocking column specimens on the shake table at EQUALS lab, University of Bristol.
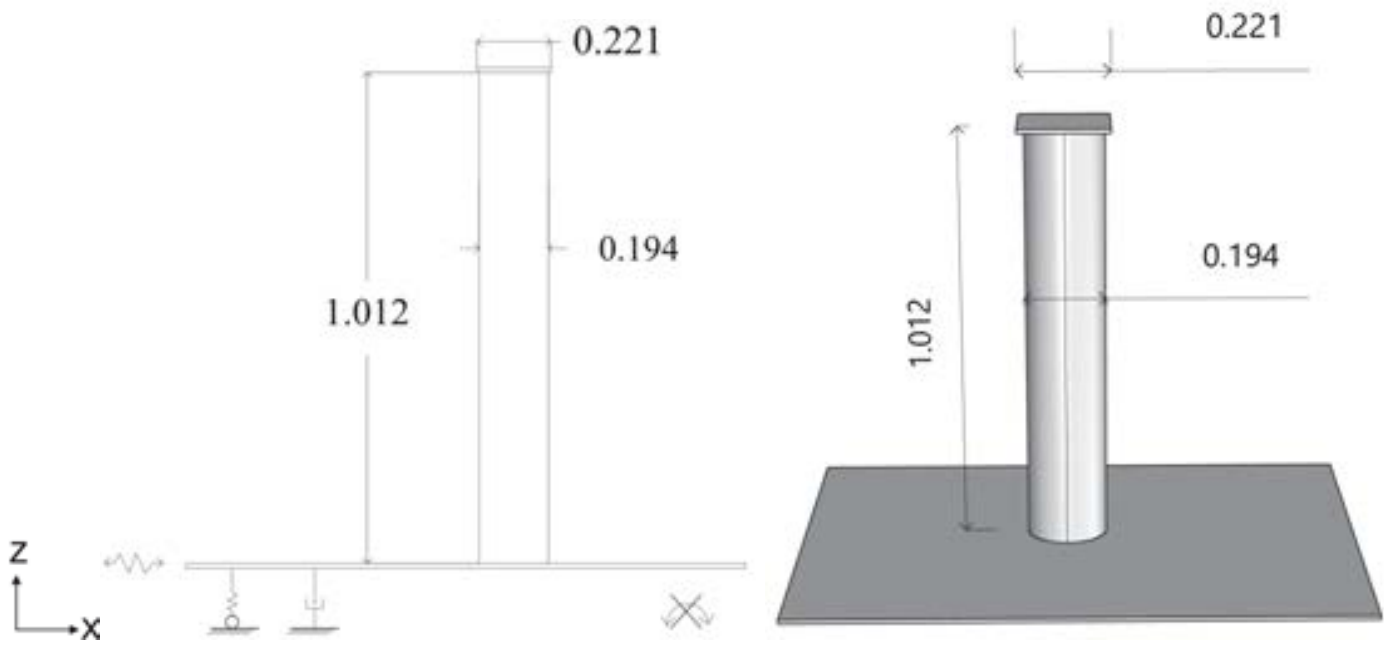

Figure 3. Left: Schematic representation of the rocking column, the constraint of the flat base and the springdashpot system bellow the base; Right: Dimensions (in m) of the tested specimen.

In this parametric analysis, the coefficient of friction $\mu$ was varied from 0.3 to 2 . Not all the above values are realistic, but the analysis explores the influence of extreme values of the modelling parameters on the rocking response. The damping ratio $\zeta$ corresponding to the vertical vibration mode (i.e. radiation damping) was set to $\zeta=1 \%$. This damping should not be confused with Rayleigh, which was equal to zero in all tests.

\section{RESULTS}

\subsection{Deterministic Comparison}

Figure 4 presents scatter plots that compare the experimental to the numerical results for different values of the critical modeling parameter (i.e., friction coefficient). The investigated response parameters are the maximum displacement $\left(u_{\max }\right)$ at the top of the rocking column, 
and the residual displacement after the end of the excitation $\left(u_{r e s}\right)$, both measured in meters. In the following plots, "OT" denotes overturning of the specimen. In all scatter plots, the horizontal axis corresponds to the experimental results, whereas the vertical to the numerical ones.

It is evident that the numerical results are moderately correlated to the experimental ones. Moreover, similarly to previous studies, the numerical model often fails to predict overturning. However, the relevant question in earthquake engineering is not whether the model is accurate but whether it is biased and whether it induces more uncertainty than the ground motion. Comparing the results of individual ground motions, it is not possible to identify clear patterns of the influence of the coefficient of friction on the maximum response of the body. Most importantly, minor changes in the coefficient of friction, lead to very large changes in the response.

\subsection{Statistical Comparison}

When the numerical results are statistically assessed, clear trends emerge (Figure 5), similarly to what was observed for the planar rocking model by Yim et al [89] as early as in 1980. An increase of the friction coefficient leads to an increase of the maximum displacement of the rocking column (Figure 5, left). The residual displacement does not seem to depend on the coefficient of friction, provided that there is no overturn. Hence, neglecting sliding (i.e. using a very high value for $\mu$ ) is a conservative modelling approach, at least in terms of maximum displacement and prediction of overturning probability.
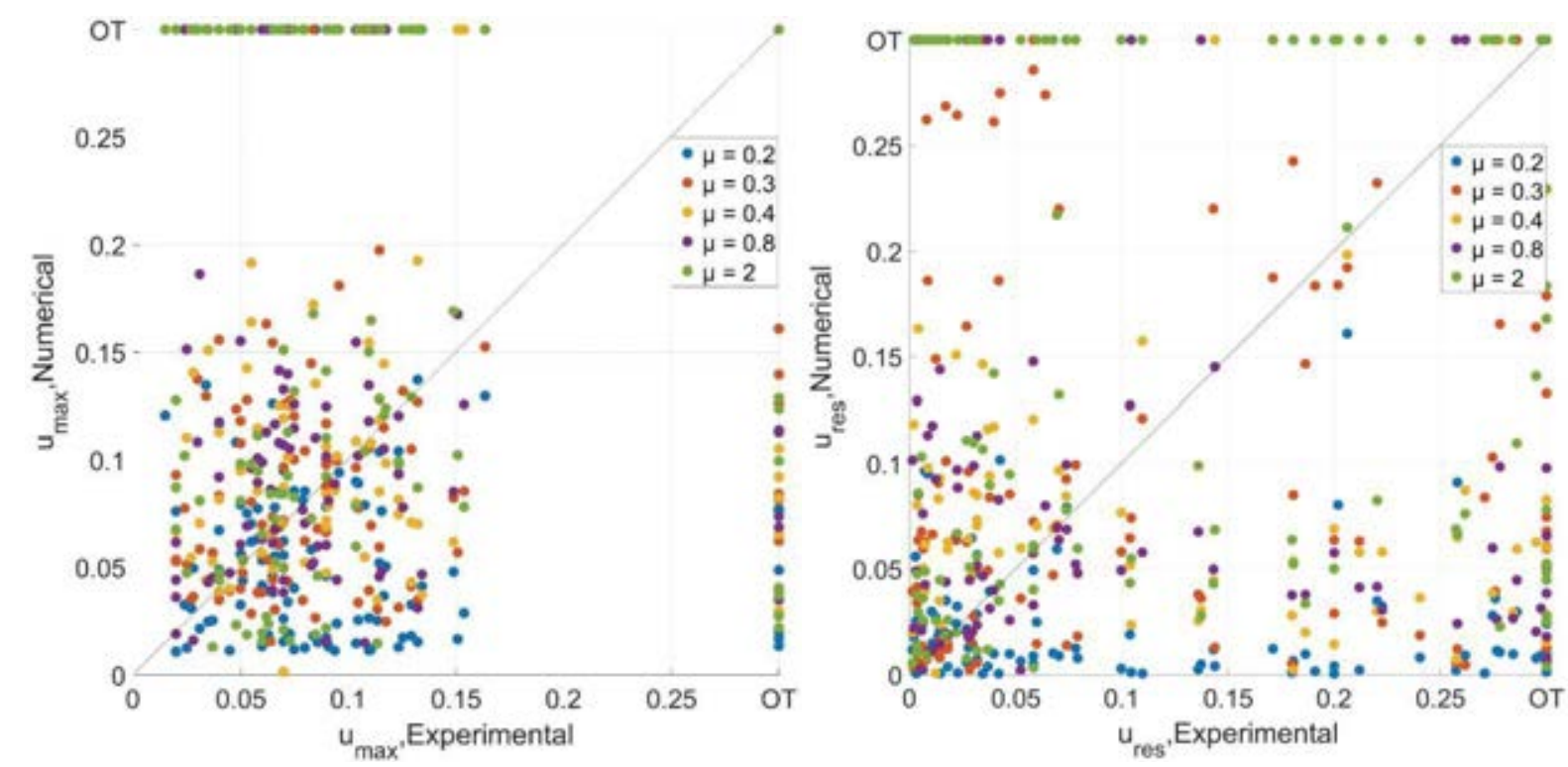

Figure 4. Deterministic comparison for experimental and numerical results of the columns. Sensitivity analysis for friction coefficient. Left: Maximum Displacement, Right: Residual Displacement 

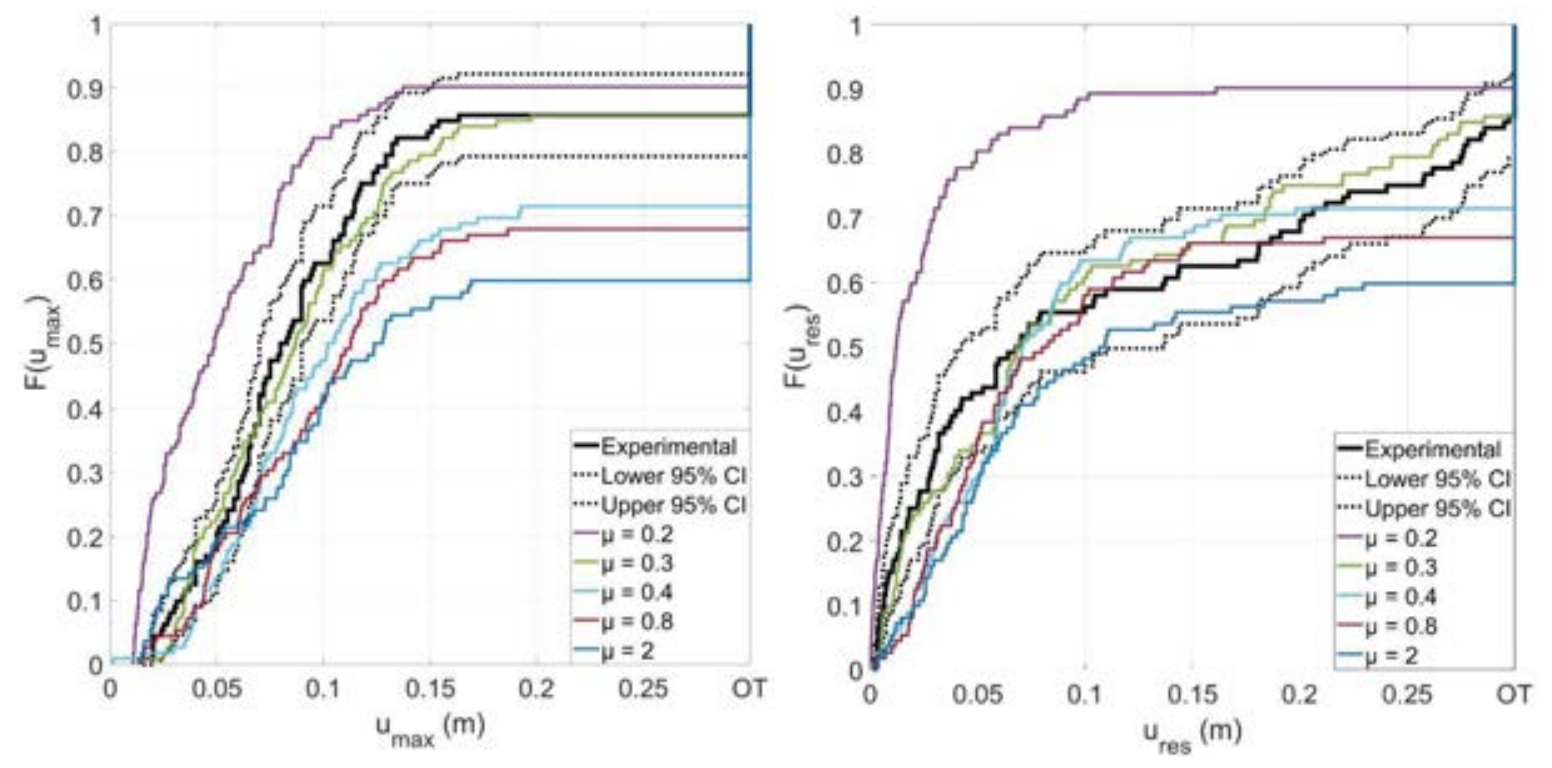

Figure 5. Statistical comparison for experimental and numerical results of the columns. Sensitivity analysis for friction coefficient. Left: Maximum Displacement, Right: Residual Displacement

\section{CONCLUSIONS}

The presented numerical model simulates the response of a free-standing cylindrical column. The column had a slenderness ratio of $\alpha=0.2$, and, during testing, it was free to slide and rock in all directions. It is shown that the model performs poorly when it is deterministically assessed based on its ability to predict the maximum displacement at the top of the column. However, it can perform well, when it is evaluated based on its ability to predict the CDF of the maxima of the response to a set of ground motions.

The friction coefficient between the rocking block and the supporting surface was varied numerically and its influence was assessed with a large number of non-linear time-history analyses. Even though the exact value of the friction coefficient significantly influences the deterministic response, it affects the statistical response only moderately. The CDF curves show that an increase of the friction coefficient amplifies uplifting and leads to larger maximum rocking displacements, thus making the model more conservative. A friction coefficient equal to $\mu=0.3$ and a radiation damping equal to $\zeta=1 \%$ leads to the optimal match between experimental and numerical results.

\section{REFERENCES}

[1] Milne, J. (1885): Seismic experiments. Trans. Seismol. Soc. Jpn., 8, 1-82

[2] Makris, N. (2014): A half-century of rocking isolation. Earthquakes and Structures, 7(6), 1187-1221.

[3] Housner, GW. (1963): The behavior of inverted pendulum structures during earthquakes. Bull Seismol Soc Am. 53(2): 403 - 417.

[4] Konstantinidis, D., Makris, N. (2009): Experimental and analytical studies on the response of free-standing laboratory equipment to earthquake shaking. Earthquake Engng Struct. Dyn. 38:827-848. DOI: 10.1002/eqe.871 
[5] Konstantinidis, D., Makris, N. (2010): Experimental and analytical studies on the response of $1 / 4$-scale models of free-standing laboratory equipment subjected to strong earthquake shaking. Bull Earthquake Eng. 8:1457-1477 DOI 10.1007/s10518-0109192-8

[6] Di Sarno, L., Magliulo, G., D'Angela, D., Cosenza, E. (2019): Experimental assessment of the seismic performance of hospital cabinets using shake table testing. Earthq Eng Struct Dyn. 48(1):103-123.

[7] Fragiadakis, M, Diamantopoulos, S. Fragility and risk assessment of freestanding building contents. Earthquake Engng Struct Dyn. 2020; 49: 1028 - 1048. https://doi.org/10.1002/eqe.3276

[8] Di Sarno, L., Petrone, C., Magliudo, G., Manfredi, G. (2015) Dynamic properties of typical consultation room medical components. Engineering Structures, Volume 100, 1 October 2015, Pages 442-454, https://doi.org/10.1016/j.engstruct.2015.06.036

[9] Cosenza, E., Di Sarno, L., Maddaloni, G., Magliulo, G., Petrone, C., and Prota, A. (2014), Shake table tests for the seismic fragility evaluation of hospital rooms, Earthquake Engng Struct. Dyn., 44, 23- 40, doi: 10.1002/eqe.2456

[10] Wittich CE, Hutchinson TC. Shake table tests of stiff, unattached, asymmetric structures. Earthq Eng Struct Dyn. 2015; 44(14): 2425- 2443.

[11] Bao, Y., \& Konstantinidis, D. (2020). Dynamics of a sliding - rocking block considering impact with an adjacent wall. Earthquake Engineering \& Structural Dynamics, 49(5), 498-523.

[12] D'Angela, D., Magliulo, G., \& Cosenza, E. (2021). Towards a reliable seismic assessment of rocking components. Engineering Structures, 230, 111673.

[13] Cocuzza Avellino, G., Cannizzaro, F., Di Martino, A., Valenti, R., Paternò, E., Caliò, I., \& Impollonia, N. (2021). Numerical and Experimental Response of Free-Standing Art Objects Subjected to Ground Motion. International Journal of Architectural Heritage, $1-16$.

[14] Voyagaki, E., Kloukinas, P., Dietz, M., Dihoru, L., Horseman, T., Oddbjornsson, O., ... \& Steer, A. (2018). Earthquake response of a multiblock nuclear reactor graphite core: experimental model vs simulations. Earthquake Engineering \& Structural Dynamics, 47(13), 2601-2626.

[15] Bao, Y., \& Konstantinidis, D. (2020). Dynamics of a sliding - rocking block considering impact with an adjacent wall. Earthquake Engineering \& Structural Dynamics, 49(5), 498-523.

[16] Linde, S. A., Konstantinidis, D., \& Tait, M. J. (2020). Rocking response of unanchored building contents considering horizontal and vertical excitation. Journal of Structural Engineering, 146(9), 04020175.

[17] Stefanou, I., Psycharis, I., Georgopoulos, IO. (2011): Dynamic response of reinforced masonry columns in classical monuments. Construct Build Mater 25(12):4325 - 4337.

[18] DeJong MJ. (2012): Seismic response of stone masonry spires: analytical modeling. Eng Struct. 40:556 - 565. 
[19] Tondelli M, Beyer K, DeJong M. (2016): Influence of boundary conditions on the outof-plane response of brick masonry walls in buildings with RC slabs. Earthq Eng Struct Dynam. 45(8):1337 - 1356.

[20] Casapulla, C., Giresini, L., Lourenço, PB. (2017): Rocking and kinematic approaches for rigid block analysis of masonry walls: state of the art and recent developments. Buildings. 7(3):69

[21] Kalliontzis D, Schultz AE. (2017): Characterizing the in-plane rocking response of masonry walls with unbonded posttensioning. J Struct Eng. 143(9):04017110.

[22] Mehrotra A, DeJong MJ. (2018): The influence of interface geometry, stiffness, and crushing on the dynamic response of masonry collapse mechanisms. Earthq Eng Struct Dynam.47(13):2661 - 2681.

[23] Giresini, L., Sassu, M., \& Sorrentino, L. (2018). In situ free-vibration tests on unrestrained and restrained rocking masonry walls. Earthquake Engineering \& Structural Dynamics, 47(15), 3006-3025.

[24] Čeh, N., Jelenić, G., \& Bićanić, N. (2018). Analysis of restitution in rocking of single rigid blocks. Acta Mechanica, 229(11), 4623-4642.

[25] Jaimes, M. A., Chávez, M. M., Peña, F., \& García-Soto, A. D. (2021). Out-of-plane mechanism in the seismic risk of masonry facades. Bulletin of Earthquake Engineering, 19(3), 1509-1535.

[26] Ma, Q. T., Parshottam, S., \& Montalla, M. (2018, June). Modelling Rocking Behaviour using Physics Engine Simulation. In Eleventh US National Conference on Earthquake Engineering. Earthquake Engineering Research Institute.

[27] Mouzakis HP, Psycharis IN, Papastamatiou DY, Carydis PG, Papantonopoulos C, Zambas C. (2002): Experimental investigation of the earthquake response of a model of a marble classical column. Earthq Eng Struct Dynam.31(9):1681 - 1698.

[28] Funari, M. F., Spadea, S., Lonetti, P., Fabbrocino, F., \& Luciano, R. (2020). Visual programming for structural assessment of out-of-plane mechanisms in historic masonry structures. J. Build. Eng. , 31, 101425.

[29] Papantonopoulos C, Psycharis IN, Papastamatiou DY, Lemos JV, Mouzakis HP. (2002): Numerical prediction of the earthquake response of classical columns using the distinct element method. Earthq Eng Struct Dynam. 31(9):1699 - 1717.

[30] Vassiliou MF, Makris N. (2012): Analysis of the rocking response of rigid blocks standing free on a seismically isolated base. Earthq Eng Struct Dynam. 41(2):177 - 196.

[31] Drosos, V.A., Anastasopoulos, I. (2015): Experimental investigation of the seismic response of classical temple columns. Bull Earthquake Eng 13, 299-310. https://doi.org/10.1007/s10518-014-9608-y

[32] Drosos V, Anastasopoulos I (2014): Shaking table testing of multi-drum columns and portals. Earthquake Engineering \& Structural Dynamics, 43(11):1703-1723.

[33] Psycharis IN, Fragiadakis M, Stefanou I. Seismic reliability assessment of classical columns subjected to near-fault ground motions. Earthquake Eng Struct Dyn. 2013; 42(14): 2061-2079. 
[34] Sarhosis, V., Baraldi, D., Lemos, J.V., Milani, G. (2019). Dynamic behaviour of ancient freestanding multi-drum and monolithic columns subjected to horizontal and vertical excitations. Soil Dynamics and Earthquake Engineering, Volume 120, May 2019, Pages 39-57, https://doi.org/10.1016/j.soildyn.2019.01.024

[35] Bantilas, KE., Kavvadias, IE., Vasiliadis, LK. (2020): Seismic response of elastic multidegree of freedom oscillators placed on the top of rocking storey. Earthquake Engng Struct Dyn.1- 19. https://doi.org/10.1002/eqe.3400

[36] Bachmann, JA., Vassiliou, MF., Stojadinović, B. (2017): Dynamics of rocking podium structures. Earthquake Engng Struct. Dyn., 46: 2499- 2517. doi: 10.1002/eqe.2915.

[37] Bachmann, JA, Vassiliou, MF, Stojadinovic, B. (2019): Rolling and rocking of rigid uplifting structures. Earthquake Engng Struct Dyn. 2019 48: 1556- 1574. https://doi.org/10.1002/eqe.3213

[38] Makris, N., Aghagholizadeh, M. (2017): The dynamics of an elastic structure coupled with a rocking wall. Earthquake Engng Struct. Dyn., 46: 945-962. doi: 10.1002/eqe.2838.

[39] Di Egidio, A., Pagliaro, S., Fabrizio, C., \& de Leo, A. M. (2020). Seismic performance of frame structures coupled with an external rocking wall. Engineering Structures, 224, 111207.

[40] Makris, N., Vassiliou, MF. (2013): Planar rocking response and stability analysis of an array of free - standing columns capped with a freely supported rigid beam. Earthq Eng Struct Dyn. 42(3): 431 - 449.

[41] Makris, N., Vassiliou, MF. (2012): Are some top-heavy structures more stable? Journal of Structural Engineering. https://doi.org/10.1061/(ASCE)ST.1943-541X.0000933

[42] Makris, N., Vassiliou, MF. (2014): Dynamics of the rocking frame with vertical restrainers. J Struct Eng. 141(10):04014245.

[43] Dimitrakopoulos EG, Giouvanidis AI. (2015): Seismic response analysis of the planar rocking frame. J Eng Mech. 2015; 141(7):04015003.

[44] Giouvanidis AI, Dimitrakopoulos EG. (2017): Seismic performance of rocking frames with flag - shaped hysteretic behavior. J Eng Mech. 143(5):04017008.

[45] Reggiani Manzo, N, Vassiliou, MF. Displacement - based analysis and design of rocking structures. Earthquake Engng Struct Dyn. 2019; 48: 1613 - 1629. https://doi.org/10.1002/eqe.3217

[46] Reggiani Manzo, N, Vassiliou, MF. (2021): Simplified analysis of bilinear elastic systems exhibiting negative stiffness behavior. Earthquake Engng Struct Dyn. 2021; 50: 580-600. https://doi.org/10.1002/eqe.3347

[47] Thomaidis, IM., Kappos, AJ., Camara, A. (2020): Dynamics and seismic performance of rocking bridges accounting for the abutment - backfill contribution. Earthquake Engng Struct Dyn 49:1161-1179

[48] Giouvanidis, A. I., \& Dong, Y. (2020). Seismic loss and resilience assessment of singlecolumn rocking bridges. Bulletin of earthquake engineering, 18, 4481-4513. 
[49] Kashani, M. M., Gonzalez-Buelga, A., Thayalan, R. P., Thomas, A. R., \& Alexander, N. A. (2018). Experimental investigation of a novel class of self-centring spinal rocking column. J. Sound. Vib, , 437, 308-324.

[50] Giouvanidis, A. I., \& Dimitrakopoulos, E. G. (2018). Rocking amplification and strong-motion duration. Earthquake Engineering \& Structural Dynamics, 47(10), 20942116.

[51] Thiers-Moggia, R., \& Málaga-Chuquitaype, C. (2019). Seismic protection of rocking structures with inerters. Earthquake Engineering \& Structural Dynamics, 48(5), 528547.

[52] Aghagholizadeh, M. (2020). A finite element model for seismic response analysis of vertically-damped rocking-columns. Engineering Structures, 219, 110894.

[53] Thiers-Moggia, R., \& Málaga-Chuquitaype, C. (2020). Seismic control of flexible rocking structures using inerters. Earthquake Engineering \& Structural Dynamics, 49(14), 1519-1538.

[54] Zhou, Y., Zhang, J., Cheng, S., He, H., Dong, Z., \& Qiang, H. (2020, January). Seismic Response of Rocking Double-Column Bridge Bents with External Hysteretic Dissipaters. In 2020 International Conference on Intelligent Transportation, Big Data \& Smart City (ICITBS) (pp. 353-357). IEEE.

[55] Xie, Y., Zhang, J., DesRoches, R., \& Padgett, J. E. (2019). Seismic fragilities of single-column highway bridges with rocking column-footing. Earthquake Engineering \& Structural Dynamics, 48(7), 843-864.

[56] Xia, X., Wu, S., Shi, J., Jia, J., Chen, X., \& Ma, H. (2020). Seismic response of rocking isolated railway bridge piers with sacrificial components. Earthquake Engineering and Engineering Vibration, 19(4), 1005-1015.

[57] Thiers-Moggia, R., \& Málaga-Chuquitaype, C. (2020). Dynamic response of posttensioned rocking structures with inerters. International Journal of Mechanical Sciences, 187, 105927.

[58] Makris, N., Vassiliou, MF. (2015): Dynamics of the rocking frame with vertical restrainers. Journal of Structural Engineering https://doi.org/10.1061/(ASCE)ST.1943$541 X .0001231$

[59] Vassiliou, MF., Makris, N. (2015): Dynamics of the vertically restrained rocking column. Journal of Engineering Mechanics https://doi.org/10.1061/(ASCE)EM.19437889.0000953

[60] Makris, N., Aghagholizadeh M. (2019): Effect of supplemental hysteretic and viscous damping on rocking response of free-standing columns. Journal of Engineering Mechanics https://doi.org/10.1061/(ASCE)EM.1943-7889.0001596

[61] Acikgoz, S., DeJong, M. (2012): The interaction of elasticity and rocking in flexible structures allowed to uplift Earthquake Engng Struct. Dyn. 41:2177-2194 DOI: $10.1002 /$ eqe. 2181

[62] Vassiliou, MF., Mackie KR., Stojadinović B. (2014): Dynamic response analysis of solitary flexible rocking bodies: modeling and behavior under pulse-like ground excitation Earthquake Engng Struct. Dyn. 43:1463-1481 DOI: 10.1002/eqe.2406 
[63] Vassiliou, MF., Truniger, R., Stojadinović, B. (2015): An analytical model of a deformable cantiléver structure rocking on a rigid surface: development and verification Earthquake Engng Struct. Dyn. 44:2775-2794 DOI: 10.1002/eqe.2608

[64] Truniger, R., Vassiliou, MF., Stojadinović, B. (2015): An analytical model of a deformable cantiléver structure rocking on a rigid surface: experimental validation Earthquake Engng Struct. Dyn 44:2795-2815 DOI: 10.1002/eqe.2609

[65] Avgenakis, E., \& Psycharis, I. N. (2020). An integrated macroelement formulation for the dynamic response of inelastic deformable rocking bodies. Earthquake Engineering \& Structural Dynamics, 49(11), 1072-1094.

[66] Chatzis, MN., Smyth, AW. (2012): Modeling of the 3D rocking problem. International Journal of Non-linear Mechanics. 47(4):85-98.

[67] Chatzis MN, Smyth AW. (2012): Three-dimensional dynamics of a rigid body with wheels on a moving base. Journal of Engineering Mechanics 2012; 139(4):496-511.

[68] Vassiliou, MF., Burger, S., Egger, M., Bachmann, J., Broccardo, M., Stojadinović, B. (2017): The three-dimensional behavior of inverted pendulum cylindrical structures during earthquakes. Earthquake Engng Struct. Dyn., 46: 2261-2280. doi: 10.1002/eqe.2903.

[69] Vassiliou, MF. (2018): Seismic response of a wobbling 3D frame. Earthquake Engng Struct Dyn. 47: 1212-1228. https://doi.org/10.1002/eqe.3013

[70] Messina, E., Chioccarelli, E., Baltzopoulos, G., \& Vecchio, A. (2020). Numerical analysis of the dynamics of rigid blocks subjected to support excitation. Applied Numerical Mathematics, 155, 29-37.

[71] Bachmann, J.A., Strand, M., Vassiliou, M.F., Broccardo, M., Stojadinović, B. (2017): Is rocking motion predictable? Earthquake Engng Struct Dyn.47: 535-552. DOI: $10.1002 /$ eqe. 2978

[72] Del Guidice, L., Vassiliou, MF. (2020): Mechanical properties of 3D printed material with binder jet technology and potential applications of additive manufacturing in seismic testing of structures. Additive Manufacturing. https://doi.org/10.1016/j.addma.2020.101714

[73] Del Giudice, L., Wrobel, R., Leinenbach, C., \& Vassiliou, M. F. (2020). Static testing of additively manufactured microreinforced concrete specimens for statistical structural model validation at a small scale. In 8th International Conference on Advances in Experimental Structural Engineering (8AESE).

[74] Agalianos, A., Psychari, A., Vassiliou, MF., Stojadinović, B., Anastasopoulos, I. (2017): Comparative assessment of two rocking isolation techniques for a motorway overpass bridge Front. Built Environ. https://doi.org/10.3389/fbuil.2017.00047

[75] Thomaidis, IM., Camara, A., Kappos, AJ. (2018): Simulating the rocking response of rigid bodies using general-purpose finite element software. $16^{\text {th }}$ European conference on Earthquake Engineering

[76] Pappas, A., Sextos, A., da Porto, F., Modena, C. (2017): Efficiency of alternative intensity measures for the seismic assessment of monolithic free-standing columns. Bull Earthquake Eng 15:1635-1659 
[77] Sextos, A.G., Manolis, G.D., Athanasiou, A., Ioannidis, N. (2017): Seismically inducd uplift effects on nuclear power plants. Part 1: Containment building rocking spectra, Nuclear Engineering and Design, https://doi.org/10.1016/j.nucengdes.2016.12.035

[78] Sextos, A.G., Manolis, G.D., Athanasiou, A., Ioannidis, N. (2017): Seismically inducd uplift effects on nuclear power plants. Part 2: Demand on internal equipment, Nuclear Engineering and Design, https://doi.org/10.1016/j.nucengdes.2016.12.036

[79] Sieber, M, Klar, S, Vassiliou, MF, Anastasopoulos, I. (2020) Robustness of simplified analysis methods for rocking structures on compliant soil. Earthquake Engng Struct Dyn. 2020; 49: 1388- 1405. https://doi.org/10.1002/eqe.3294

[80] Vassiliou, MF, Broccardo, M, Cengiz, C, et al (2020): Shake table testing of a rocking podium: Results of a blind predictioncontest. Earthquake Engng Struct Dyn. 120. https://doi.org/10.1002/eqe.3386

[81] Vassiliou, M. F., Cengiz, C., Dietz, M., Dihoru, L., Broccardo, M., Mylonakis, G., ... \& Stojadinovic, B. (2020). Dataset from the shake table tests of a rocking podium structure. Earthquake Spectra, 8755293020988017.

[82] Zhong, C, Christopoulos, C. (2020): Finite element analysis of the seismic shake-table response of a rocking podium structure. Earthquake Engng Struct Dyn. 1- 8. https://doi.org/10.1002/eqe.3397

[83] Malomo, D, Mehrotra, A, DeJong, MJ. (2020): Distinct element modeling of the dynamic response of a rocking podium tested on a shake table. Earthquake Engng Struct Dyn. 1-7. https://doi.org/10.1002/eqe.3404

[84] Vassiliou, MF., Cengiz, C., Dietz, M. et al. (2021) Dataset from shake table tests of free-standing rocking bodies. Earthquake Spectra (under review)

[85] Rezaeian S, Der Kiureghian A. (2008): A stochastic ground motion model with separable temporal and spectral nonstationarities. Earthq Eng Struct Dyn. 2008;37(13):15651584 .

[86] Broccardo M, Dabaghi M. (2017) A spectral-based stochastic ground motion model with a non-parametric time-modulating function. In: $12^{\text {th }}$ International Conference on Structural Safety and Reliability; Vienna; 2017:1-10.

[87] ABAQUS 2019 (2019). Standard User's Manual. Providence, RI: Dassault Systèmes Simulia Corp.,

[88] Vassiliou, M. F., Mackie, K. R., and Stojadinović, B. (2017): A finite element model for seismic response analysis of deformable rocking frames. Earthquake Engng Struct. Dyn., 46: 447-466. doi: 10.1002/eqe.2799.

[89] Yim, C. S., Chopra, A. K., \& Penzien, J. (1980). Rocking response of rigid blocks to earthquakes. Earthquake Engineering \& Structural Dynamics, 8(6), 565-587. 